\title{
Teacher-Parent Interactions in Taiwan: A Qualitative Investigation of Teachers' Perspectives
}

\author{
Pi-Ju Wu \\ Graduate Institute of Education, National Changhua University of Education, Taiwan
}

Copyright $(\subset) 2015$ Horizon Research Publishing All rights reserved.

\begin{abstract}
Because the importance of parental involvement in education has been emphasized recently in Taiwan, the nature of teacher-parent interactions has changed. The current study describes teacher-parent interactions from teacher perspectives in grades 1-12 in Taiwan. Data were collected from 50 teachers using open-ended questionnaires. Thematic analysis was used to analyze the data. Nine themes regarding the experiences of teachers in their interactions with parents were identified, namely, initiative of interaction, cause of interaction, parental role, consideration before action, social network, action strategy, outcome of interaction, reflection on interaction, and suggestion for preservice teachers. Four important issues related to teacher-parent interactions are discussed further.
\end{abstract}

Keywords Parent-Teacher Interaction, Parent- Teacher Relationship, Parent Involvement

\section{Introduction}

Parent involvement has become a widespread movement across many countries worldwide [6, 16, 24]. From an economic perspective, schools could obtain potential cost-benefit resources from parent involvement; from the sociological perspective, parent involvement is regarded as one of the mechanisms connecting student academic achievement with the social economic background of their families [17]. After reviewing research on parent involvement in 20 nations, Sanders and Epstein [24] concluded that most nations began their parent involvement policies with mechanical systems such as school choice and school decision making; however, these policies are not able to replace the more responsive mechanisms, which enable all parents to acquire information on the learning and development of their children through regular communication with teachers. Shumow and Harris [27] also identified communication between parents and teachers on the child as one of the most important methods of parent involvement by second and fifth grade teachers. Therefore, everyday interaction between teachers and parents is a key element of parent involvement.

Education reform has been ongoing in Taiwan for more than two decades. Decentralization is one of the major characteristics of the educational reform movement. School-based curriculum development has been emphasized and teachers now have more power in their teaching decisions, thus enhancing their professional autonomy. Decentralization has also resulted in increasing the educational involvement of parents. Many education reform groups have advocated increasing the rights of parents to influence the schooling of their children. The Educational Fundamental Act promulgated in 1999 is a response to that claim. Article 8 of the Act states that parents have the responsibility to provide guidance to their children during the period of national compulsory education for their children and to select the form and content of education and to participate in the educational affairs of schools for the best wellbeing of their children. In 2006, the Regulations of Parental Participation in Educational Affairs of Schools during the Period of National Compulsory Education were enacted by the Ministry of Education. These regulations require every school to actively communicate with parents and enable parents to make important decisions on the education of their children. Parents are empowered to protect the rights and interests of their children in schooling, including the rights of school choice, decision-making, objection, association, educational consumption, and educational experts [10]. These requirements differ from traditional Chinese culture, in which teachers are highly respected and parents typically do not question what and how their children are taught in schools. As a consequence, the nature of teacher-parent interactions has greatly changed. For example, Chen [10] interviewed six elementary teachers and found that the teachers developed various political means to deal with parent empowerment. Although the strategy of open communication and transparency has the potential to improve the cooperative relationship between teachers and parents, teacher over compliance with parents might undermine their professional position. Through participant conservation and interviews in an elementary school, Liang [21] concluded that teachers tend to use the 
strategies of confrontation, favorism, and compliance to meet with the demands of parental empowerment. Chang [7] indicated that parent-teacher interactions at the kindergarten level were affected by the discourse of parent education and marketization of early childhood education. Because parents have enacted their rights of school choice and educational involvement based on their knowledge of childhood education, teachers must first understand and meet the educational expectations of parents and then use their professional knowledge to educate parents. The first-grade classroom ethnography of Liou and Ting [22] shows that teacher-parent interactions were often caused by practical needs such as communicating on student performance at school and attending class or school activities. Because most previous studies have been conducted in kindergarten and elementary school settings, there is still a need to understand how Taiwanese teachers interact with parents, particularly beyond the level of elementary education.

This study describes teacher-parent interactions from teacher perspectives in grades 1-12 in Taiwan. The experiences of teachers in their interactions with parents provides useful information for designing teacher professional development programs and improving preservice teacher education.

\section{Theoretical Framework}

The ecological systems theory of Bronfenbrenner $[4,5]$ describes the complex environments surrounding a child and the embedded structures which influence each other. The ecological environments consist of five systems, including the microsystem, which refers to the interactions a child experiences in a face-to-face setting; the mesosystem, which refers to the linkages occurring between at least two microsystems; the exosystem, which refers to the linkages occurring between two or more settings, the least of which does not contain the child, but in which the microsystem surrounding the child is affected; the macrosystem, which refers to the overarching pattern of the three systems; and the chronosystem, which refers to the change over time in the child and the four systems. According to the ecological systems theory, family and school are two microsystems in child development. Teacher-parent interactions, which result in connections between the two microsystems, belong to one of the mesosystems. This mesosystem not only affects the development of the child by interacting and changing its microsystems, but also interacts with its exosystems, macrosystems, and chronosystems.

Epstein [11, 13] proposed the theory of overlapping spheres of influence to explain school, family, and community partnerships. The theoretical model includes external and internal structures and locates the student at the center. The external structure consists of three spheres representing family, school, and community, which can be pulled together or pushed apart by the forces of experience, philosophy, and time, and the practices of families, schools, and communities. The internal structure describes institutional and interpersonal communication occurring within and across the boundaries of schools, families, and communities. The external and internal structures are related to each other. The current study focuses on two of the three spheres of influence, including school and family contexts and specifically explores the interactions between teachers and parents at the interpersonal level.

\section{Method}

A survey was conducted to understand how teachers interact with parents and how teachers reflect upon these interactions. The survey asked the participants to write up one impressive event that occurred during their interactions with parents through a series of open-ended questions.

\subsection{Participants}

The participants in this study were 50 teachers who consented to provide information on working with parents. They were recruited through their colleague recommendations that they were willing to share their personal experience stories of teacher-parent interactions. Their background information is reported in Table 1.

Table 1. Participants' Background

\begin{tabular}{|c|c|c|c|}
\hline Attributes & Group & Number & Percentage \\
\hline \multirow{2}{*}{ Gender } & Female & 43 & $86 \%$ \\
\hline & Male & 7 & $14 \%$ \\
\hline \multirow{4}{*}{ Age } & Under 31 & 13 & $26 \%$ \\
\hline & $31-40$ & 21 & $42 \%$ \\
\hline & $41-50$ & 10 & $26 \%$ \\
\hline & Above 50 & 3 & $6 \%$ \\
\hline \multirow{5}{*}{$\begin{array}{l}\text { Years in } \\
\text { Teaching }\end{array}$} & Under 6 & 16 & $32 \%$ \\
\hline & $6-10$ & 7 & $14 \%$ \\
\hline & $11-15$ & 10 & $20 \%$ \\
\hline & $16-20$ & 8 & $16 \%$ \\
\hline & Above 20 & 9 & $18 \%$ \\
\hline \multirow{2}{*}{$\begin{array}{c}\text { Education } \\
\text { Level }\end{array}$} & Undergraduate & 22 & $44 \%$ \\
\hline & Graduate & 28 & $56 \%$ \\
\hline \multirow{3}{*}{$\begin{array}{c}\text { Teaching } \\
\text { Level }\end{array}$} & $\begin{array}{c}\text { Elementary } \\
\text { School }\end{array}$ & 15 & $30 \%$ \\
\hline & $\begin{array}{c}\text { Junior High } \\
\text { School }\end{array}$ & 29 & $58 \%$ \\
\hline & High School & 6 & $12 \%$ \\
\hline Total & & 50 & $100 \%$ \\
\hline
\end{tabular}

Forty-three of the participants were women $(86 \%)$ and seven were men (14\%). Their ages ranged from 26 to 57 and the largest age range was $31-40(42 \%)$. The number of years they were engaged in teaching varied from 1 to 30 and 16 out of the 50 participants had taught for five years or 
less $(32 \%)$. Twenty-eight of the participants had master degrees or took graduate courses $(56 \%)$ and 22 had bachelor degrees $(44 \%)$. Twenty-nine of the participants taught in junior high schools (58\%), 15 taught in elementary schools (30\%), and six taught in high schools (12\%).

\subsection{Instruments}

The Write up of my Teaching Experience Questionnaire was constructed as the prime data-collection instrument for this study. The questionnaires were mailed or e-mailed to participants and included eight open-ended questions to which participants could respond in any way they wished. The questions are as follows:

- Could you describe one of the most impressive or controversial events related to your interactions with parents?

- What was the cause of the event?

- What actions did you take at that time? What was the consequence?

- What were your considerations when you decided your action strategies?

- Did you discuss the event with someone, such as colleagues or family members? If you did, what were their reactions? Did their reactions affect your actions?

- In retrospect, did you deal with the event appropriately? If a similar event occurs again, will you change your approach in dealing with it?

- What are the implications of the event in your interactions with parents?

- What suggestions do you have on teacher-parent interactions for teacher candidates?

\subsection{Data Analysis}

Data analysis was conducted by thematic analysis. Themes are recurring patterns, topics, viewpoints, emotions, concepts, and events [2]. Data from each questionnaire were analyzed using open coding. Coded data were compared and contrasted constantly and then similar codes were combined into categories. Tentative themes were created during the coding process and were refined later when reviewing the data. The computer-assisted qualitative data analysis software, Nvivo, was used to help analyze data. The coded data were labeled as (\#1: \#2), in which \#1 refers to the identified number of participants and \#2 represents the number of paragraphs in the computer files. When quoting individual experience stories, a code name, ex. Mr./Ms. XX, was used to represent the participant teacher.

Both intra-coder consistency and inter-coder agreement were established at the beginning of data-analysis. A high school teacher who holds a master's degree in education and has experience in conducting qualitative research was invited to act as the co-coder. The data of one of the questionnaires were coded independently and the analysis results were discussed. The data of another questionnaire were then coded independently again and the percentage of inter-coder agreement was calculated. The inter-coder agreement approached $70 \%$. To achieve intra-coder consistency, the data of each questionnaire were coded repeatedly until no variation was found in the coding result compared to that of previous coding.

\section{Results}

The analysis of qualitative data from open-ended questionnaires completed by 50 teachers of grades 1-12 revealed nine themes regarding their experiences of and reflections on their interactions with parents in Taiwan. The nine themes are as follows:

\subsection{Initiative of Interaction}

When students have problems at school, teachers contact their parents; in contrast, when students perform well at school, their parents are quite willing to contact teachers [12]. Therefore, the one who initiates contact in teacher-parent interactions may be related to student positive or negative performance at school [19]. Over half of the teachers in this study initiated interaction with parents. For example, Ms. AF stated:

Because of his (one of the students in her class) bad attitude toward school learning and his low grades, as well as his bad peer relations, I asked his mother to come for a meeting. (16: 16-17)

However, $40 \%$ of the teachers expressed that parents initiated contact with them because of their concerns with teaching and learning at school. Ms. BE commented:

I received a phone call from one of my students' parents and felt the anger in his trembling voice. He asked me: "Why do you require my son to finish so much homework at one time?" He complained that his son had not finished the assignments even though the child worked for more than four hours. (25: 15)

\subsection{Cause of Interaction}

The behavioral problems of students were the prime causes of teacher-parent interactions, mentioned by $78 \%$ of the teachers. Ms. AB described that one of her students had shown considerable deviant behaviors since the beginning of the semester, such as using bad language in talking to teachers and threatening other students. The situation did not change after she admonished the student, so she sent a note to inform his parents of their son's problems. Another example was Ms. AE's experience:

When several of the girls who used to be well-behaved, turned into rule-breakers in regard to their dress and discipline, I wrote about my concerns in the teacher-parent contact booklets. However, I never received any response from their parents. (15: 16) 
Teacher-parent interactions were also caused by student academic problems. For example, Ms. KE stated that one of the parents called her to ask why her son performed poorly on a monthly examination.

\subsection{Parental Role}

Different teachers perceived parents as playing different roles in teacher-parent interactions, including the objector, collaborator, help-wanter, and pressure-maker.

Nearly half of the experiences of teachers in interacting with parents showed that parents played the role of objector. As an objector, parents might or might not monitor the everyday activities of the teachers; however, they oppose teacher approaches when they believe the decisions or practices of teachers put the wellbeing of their children at risk. Ms. DG indicated that even though she explained why the remedial courses were scheduled in the evening, a mother disagreed with her because she did not want her son to get back too late. In the following case, the father of a student expressed his disagreement by phone with Ms. BA on her approach to classroom management.

I taught at an elementary school in a high SES community. Most parents value and care about their children's education. One day, when several students made noise in my class, I used 'guilt-by-association' and grounded the entire class during recess. The next day, one of the parents of my students called me from abroad to discuss the disciplinary approach I used, after he learned about the event from his son by phone. (21: 48)

For $36 \%$ of the teachers, parents played the collaborator role in teacher-parent interactions. Those parents typically agreed with or were obedient to the opinions of the school or teachers on how to solve their child's problems. Ms. DA and Mr. JG gave two such examples:

I informed their parents first and asked them to come to school. We needed to find out why the students behaved in such a way together. Parents should cooperate with schools to deal with their children's problems. (07: 19, 28)

Each of us, including myself and two teachers at the Office of Guidance, was responsible for dealing with the two students' problems and informing their parents. We asked the parents to help us. (41: 18)

Another role the parents played, according to $14 \%$ of the teachers, was that of help-wanter. Some of the parents sought help explicitly from their child's teachers. Mr. AA stated:

His (one of his students) father was violent with his mother. The mother ran away from home and called me to help protect her child in my class. (11: 14).

However, the other parents had implicit needs for help. Although they did not ask the teachers for help, the teachers could sense their needs. Ms. AF described how one of the mothers of her students often asked for sick leave for her son and was not willing to discuss the details of the situation. Ms. AF learned later that the mother had a mental disorder and was unwilling to take medicine during that time. The mother was often under the illusion that bad men would harm her family outside their home, and so would not allow her son to go to school.

In contrast to a collaborator, approximately $10 \%$ of the teachers perceived parents to sometimes act as pressure-makers in interacting with them. The parents exercised internal and external power over the teachers and pressured the teachers to agree with them. Internal power refers to the influence of the school administration and the Parent Association (PA) over the teachers. Ms. JF recalled asking one of her students to put more effort into his school work; however, his grandparents thought she was too demanding, even though she explained her good intentions to them. They reported to the school principal. The principal and other administrators advised her to let the child alone. Mr. AC provided another example:

I was very angry that his mother replied in such an irresponsible way. However, I could not express my dissent. Otherwise, she would pressure me and the school through the PA. (13: 20)

External power refers to the influence of local councilors, mass media, and so on. The following was one of most impressive events of teacher-parent interactions that Ms. AE could recall:

Under pressure from the city councilor, I was forced to apologize to the parent for my gaffe at the principal's office. Then I was escorted by the director of Student Affairs back to the classroom and required to express my apology to the entire class. (15: 22-23)

\subsection{Consideration Before Action}

Teachers either initiated contacting parents or responded to parent actions. When deciding how to interact with or respond to parents, more than half of the teachers first considered the wellbeing of the students. Ms. CC thought that the healthy development of students was most important and did not want the marriage problems of parents to negatively affect the child. Ms. AF also stated:

I reported the case to the police because I hoped to dispel his fears as soon as possible so that he could grow up in a favorable environment. (16: 37)

Fourteen percent of the teachers tried to avoid making things worse when they interacted with the parents of students. Ms. DG recalled that she decided to react in a passive way to avoid troubles. Ms. BI also commented:

Because my competence in dealing with student problems was not enough and the student seemed to frequently get into trouble, I reported to the school administrators to prevent things from getting worse. 
(29: 34)

When interacting with parents, approximately $10 \%$ of the teachers considered the reactions and feelings of parents. Ms. $\mathrm{BH}$ said that she could empathize with the anxiety and pain of a mother, so she tolerated the mother's harsh criticism. Ms. JD's experience was as follows:

Out of consideration for the mother's dignity and feelings, I did not talk with her directly. (04: 23)

Ten percent of the teachers considered the rights and interests of the entire class when planning how to handle parents regarding student problems. Ms. JA indicated that because of the right of other students to learn, she suggested sending one of the two students to the midway class even though his parents were against her idea. Mr. CE also stated:

The student showed considerable deviant behaviors, such as screaming in class, hitting classmates, etc. To keep the class safe and to protect the right of the other students to learn, I asked the staff at the Office of Student Affairs to help separate the student from other students and called his father immediately. (35: 36)

\subsection{Social Network}

A social network consists of a definite set or sets of actors and the relation or relations defined on them (Wasserman \& Faust, 1994, p. 20). Those individuals whom one person is linked with are referred to as nodes in one's social networks and the social relationships that result from the connections among the nodes are one's social networks. Ninety percent of the teachers said that their social networks are involved in their interactions with parents. The teachers' colleagues and families comprised the major nodes in their social networks. Ms. DF and Ms. JD discussed their communications with the parents of their students with their husbands. Ms. CC commented:

I discussed this incident with my colleagues and learned about the conduct of the student's father in general. I thought that the father loved his child and would not hurt him. (33: 29)

The main functions of the teachers' social networks included providing support, making suggestions, and expressing different opinions. When they received opinions on how to act or react to their students' parents, which were similar to theirs, $44 \%$ of the teachers felt that their actions received the support of others. Mr. CB said that his family members and colleagues agreed with his principles of how to handle his students' misconduct, which included informing the students' parents and requiring the parents' cooperation. The following description was given by Ms. EA:

I caught a girl cheating on the examination and she cried, begging me not to let her parents know about it. However, I informed her parents of her misconduct and tried to let her parents know how panicked she was. However, the girl ran away from home early the next morning. I worried about her until her parents found her and I felt a sense of relief. I discussed this incident with guidance teachers at school and they approved of my decision and action. (51:32)

When others offered suggestions instead of commentaries on how to interact with students' parents, the teachers obtained information on solving problems they encountered. Ms. BC said that the director of the Office of Guidance analyzed the incident and indicated that the parent's accusation was entirely groundless and suggested that she could find out the true facts from her students. Ms. AH also stated:

Because the student's family background was so complicated, the school teachers could not solve the problems caused by his family. Therefore, my colleagues suggested that I just focus on his school life and stay in touch with his mother. (18: 32)

However, $10 \%$ of the teachers perceived that others held different opinions on how to approach or react to the incidents involving interactions with parents of students. Their differing opinions might affect teacher choices regarding action strategies and cause negative feelings. The colleagues of Ms. EA supported her dealings with one of her students cheating on an examination, but her family members disagreed with and blamed her for her decision to inform the student's parents, resulting in the student's running away from home. If the student had suffered misfortune, Ms. EA would have felt sorry for the rest of her life. The school administrators also gave the following advice to Ms. AE:

Mind your own business. Parents today spoil their children. Children are not restrained. Parents usually refuse to acknowledge their children's faults. (15:33)

Although Ms. AE did not follow their advice, she felt that her enthusiasm diminish for communicating with parents and school administrators. However, $10 \%$ of teacher interactions with parents did not involve their social networks. Ms. DC said that she did not talk of the incident with her colleagues or families because she was confident with her own principles of working with parents.

\subsection{Action Strategy}

The action strategies of teachers regarding their interactions with parents were divided into two categories: handling things alone and letting someone step in. Within the first category, $56 \%$ of the teachers tried to solve student problems by themselves, which frequently led to their interactions with parents. For example, Ms. AG interviewed her student first and found out that he was distracted because of quarrels between his parents. She visited his mother and informed the mother about her son's fears and worries. The mother promised Ms. AG to do her best not to disturb her son's learning because of her marital problems before he entered college. When the parents were not cooperative, the 
teachers focused on solving student problems on their own. Ms. JH described her action strategy:

\begin{abstract}
Since the semester began, the student had shown deviant or strange behaviors in class, such as falsifying scores on his test papers, saying sexually explicit things to girls, etc. I called his mother and she replied that her son had no such deviant behavior in elementary school and behaved as usual at home. In addition to continuing to communicate with the parents, I rearranged the student's seat and explained his condition to the classmates sitting around him to reduce their fears. I also explained his condition to other teachers who taught my class. (08: 26-27)
\end{abstract}

Other, $30 \%$ of the teachers requested someone to step in to work out problems, which were either caused by students, or resulted from related teacher-parent interactions. For example, Ms. BI said that she informed the student's grandparents about his school misconduct and asked the staff at the Office of Guidance and the Office of Student Affairs for their help. According to the description of $14 \%$ of the teachers, someone stepping in did occur without their request. Ms. CA frequently commented, "Are you dumb?" when students angered her by not replying to her repeated questions. One day, when the scenario occurred again, she received a phone call from the aunt of one of her students. The aunt said that her wording was inappropriate and unacceptable. Ms. CA tried to explain and the communication between them went nowhere. The mother of the student then came to visit Ms. CA the next day and expressed her disappointment at the inappropriate manner of the teacher. Ms. CA nearly lost her patience and just made a brief statement on how she used the phrase because students said nothing in reply to her questions. However,

The mother came to talk to the director of the Office of Academic Affairs and the director asked me to call and apologize to her...... Then the principal came to tell me that I must apologize. (31: 11-12)

When someone steps in, especially without the request of the teacher, teachers are forced to accommodate to the view of the mediators, which typically agrees with the parents. The case of Ms. CA is an example of her being forced to apologize to the student's mother. In contrast, mediators typically step in to work with teachers to solve problems because of the teacher request for help. Ms. AF said that when one of her students called her for help because his mother, who had a mental disorder, cut his clothes and books with scissors one night, she reported the case to the police. Ms. AF, accompanied by a policeman, visited the student's apartment. With the help of the policeman, she was able to "rescue" the student from a dangerous situation and temporarily separate him from his mother.

\subsection{Outcome of Interaction}

The interactions between teachers and parents influenced students, parents, and teachers. Ten of the teachers reported that the interaction sometimes solved student behavioral or academic problems. Mr. AA stated:

\section{I spoke frequently with the student to let him know that his mother cared about him and worried about his misconduct. Finally, he was able to appreciate the message I tried to communicate. He understood his parents' concern and changed his attitude toward them. His behavior improved. (11: 17)}

In contrast, seven of the teachers noted that student problems sometimes worsened because of teacher-parent interactions. Ms. AE indicated the inappropriate dress and behavior of two girls in front of the entire class. However, the girls distorted what she said and told their parents about her criticism. The parents did not believe Ms. AE's explanation and demanded that she apologize to the entire class. She felt pressured by one of the city councilors to apologize to the parents and the class:

After this incident, the entire class showed no respect for me, and other teachers who taught my class were afraid of carrying out any disciplinary policy toward those students. As a result, the entire class was out of control. (15:22)

Nine of the teachers responded that the solutions to student problems resulting from teacher-parent interactions were still in progress and the consequences were unknown. Twelve percent of the teachers expressed that parents were dissatisfied with their actions, whereas $24 \%$ noted that parents appreciated what they did. Ms. DD stated:

At that time, the manner in which both of us spoke was not very friendly. The student's mother did not agree with the way I dealt with her daughter's problem; however, I felt that her daughter deserved it, because the girl broke school regulations...... We parted on bad terms in the end. (44: 19)

In contrast, when Ms. EA did her best to explain, with help from the science teacher, why she gave the girl a demerit, the girl's mother eventually accepted her explanation. In four cases, the parents even expressed their gratitude or apologized to the teachers:

The student attempted suicide but fortunately, failed to succeed. She admitted that she lied to her father about the cause of her suicide attempt, which was not related to the disciplinary policy I adopted in my class. The father was sorry about the blame he put on me and apologized to me in front of the school administrators. (23: 23)

Two of the teachers expressed emotional fluctuation in interacting with parents. Ms. CA said that she was unwilling to apologize to the student's mother, but the principal strongly demanded that she do so. Although she briefly apologized to the mother in the principal's office, she felt sad and humiliated. By contrast, Ms. BA felt grateful that the 
student's father was willing to pay for an expensive phone bill to communicate his opinions on classroom management with her from abroad.

\subsection{Reflection on Interaction}

When reflecting on their experiences of teacher-parent interactions, $70 \%$ of the teachers expressed that they would adopt different action strategies or make slight adjustments if similar situations occurred again. Among those teachers, 16 of them would adopt different action strategies for interacting with the parents of students because they wanted to improve interaction quality, while eight teachers would change their previous actions toward improving teaching quality or the teacher-student relationship. Ms. BE, who belongs to the first category, noted:

When I recall the talk between me and the boy's mother, I think that if I could have been more patient and calm to listen to her and wait until her emotion eased, both of us might have been able to discuss things rationally. (25: 33)

Ms. BA, who belongs to the second category, said that the entire class was grounded during recess because of the wrong doing of some students. After the father of one student discussed this incident with her by phone from abroad, Ms. BA said that she would never use this kind of disciplinary strategy in her classroom management because of the importance of recess to first graders.

Nine teachers considered turning to school administrators or professionals for help. Thus, they considered alternative action strategies. Mr. CB and Ms. EA said that they would request help from school councilors and police to help solve problems. Ms. DG stated:

I will still insist on my standards of student manners and clothes; however, I will requests assistance from the school administration to remove possible parent misunderstandings. (47: 32)

Finally, five teachers thought that they would change their action from active to passive. Ms. DF was one of those examples:

If I come across similar cases, I will not be meddlesome anymore. (46: 18)

By contrast, 12 teachers saw that their actions already resulted in positive outcomes, so they did not think they needed to change their interactions with parents. Mr. AA noted:

Although the process of problem-solving was lengthy and did not obtain instant effects, the final outcomes were positive. Therefore, if I run into the same incidents again, I will probably act on my own past experience. (11: 29)

Two teachers did not consider alternative action based on their low self-efficacy for problem-solving. Ms. AH thought that students with problems grow in families with problems and teachers cannot fix those family problems. Therefore, she would focus on the wellbeing of students at school and continue to do things the same. Two teachers stated that they would not change their actions because of their professional ethics. Ms. CC expressed that she would not change her manner of dealing with parents to protect student confidentiality. Ms. DE also stated:

I will still do my best to strive for student interests. I will try to help their parents understand the purpose for my actions. After all, this is what a teacher ought to do and I cannot stop doing it because of past failures. (45: 29)

\subsection{Suggestion for preservice teachers}

The first suggestion made by more than $70 \%$ of the teachers for preservice teachers is to improve the quality and quantity of communication between teachers and parents. Teachers can use various channels for teacher-parent communication, including contact booklet, home visit, phone call, class newsletter, parent-teacher conference, and before- and after-school time. To improve the quality of teacher-parent communication, teachers need to inform parents on their children's problems and good performance, communicate with parents as soon as possible, respect and empathize with parents and their opinions, provide parents opportunities for understanding their teaching approaches, and understand students' families. Ms. CH added:

Teacher should be empathetic. If teachers expect parents to respect and support them, they need to ask themselves: How do I expect my own child to be treated by his/her teachers? (38:36)

Second, the teachers suggested that preservice teachers increase their professional knowledge and their skills in interpersonal relationships. A related suggestion is that teachers should manage their emotions adequately when interacting with students and their parents. Ms. AB stated:

Before dealing with your students' problems, you must handle your own emotions well. (12: 46)

Third, the teachers reminded preservice teachers to consult with their senior colleagues on teacher-parent interactions. Senior teachers have rich experience in interacting with students' parents, so they can be sources of practical knowledge, which younger teachers can learn from. Besides, teachers have better to seek the help of school administration whenever needed. Ms. AB stated:

Teachers need to request support from the school administration or even other institutions when they encounter complex problems related to students or their parents. They should not fight a lone battle. (12: 48)

Fourth, the teachers suggested that preservice teachers establish positive teacher-student relationships. Because teacher-parent interactions are often caused and mediated by students and their problems, maintaining good 
teacher-student relationships may benefit teachers in their interactions with parents. To establish positive relationships with students, teachers need to understand their students first. Teachers can improve teacher-student relationships with good classroom management. Seventh, the teachers reminded preservice teachers to protect themselves from being hurt in teacher-parent interactions. Ms. DF expressed:

Teachers make demands on students' learning and conduct based on their sense of responsibility for education. However, teachers should think about self-protection at all times because they hold a weak position in society. (46: 30 )

Finally, the teachers who participated in this study suggested adopting appropriate attitudes toward parents. Teachers must not overly compromise themselves with parents. Ms. DF thought that because of their lack of teaching experience, beginning teachers may not be accepted completely by parents; however, they should insist on their professional principles and not simply meet the demands of the parents without consideration. Ms. AI stated:

Stand your ground. Do not play up to the parents; otherwise, you will be manipulated by them. (19: 49)

Teachers should not have high expectations of parents. Ms. AG considered:

Every family has some troubles. Teachers should focus on educating students and not be responsible for changing or educating their parents. (17: 46)

\section{Discussion}

This study explores teacher-parent interactions from teacher perspectives in grades 1-12 in Taiwan. The results of this study indicate several noticeable issues deserving further discussion. First, when parents played the role of collaborator who tended to agree with teacher opinions in teacher-parent interactions, the teachers perceived that both of them intended to solve student problems, which initiated their interactions together. Henderson, Marburger, and Ooms [15] argued that a major part of parents playing collaborator role is to help teachers resolve their children's problems. However, this type of teacher-parent interaction seems close to the expert model in which teachers maintain control over decisions on how to solve student problems, while parents receive information and direction from teachers [18]. However, when parents acted as the objector or pressure-maker in teacher-parent interactions, the teachers often conceded that they were wrong or behaved inappropriately, particularly in cases where others stepped in to resolve the problems, which caused the interactions. Those "others" typically involve school administrators, presidents of the Parent Associations, and local assemblymen or assemblywomen who act as the mediator between teachers and parents. Their interventions, viewed as change in exosystems, often caused change in mesosystems and icrosystems, which include the teacher-parent relationship, the teacher-student relationship, and teacher-administrator relationship $[4,5]$. The different roles parents played in their interactions with teachers may result from the different goals, beliefs, attitudes, and behaviors which teachers and parents hold in different contexts [13]. This also shows one aspect of the micropolitics of teaching related to power and how teachers use it to influence others and to protect themselves [3]. The micropolitcal analysis of Chen [10] indicates that elementary school teachers develop various political strategies when interacting with parents, including types of influence, protection, and cooperation. Based on the research framework on the micropolitics of teaching proposed by Blasé [3], the roles, events, structures, and processes involved in teacher-parent interactions deserve future exploration.

Second, whether teachers or parents initiated teacher-parent interactions, the causes of the interactions always involved student behavioral or academic problems. Chen [10] also found curriculum/schoolwork and student discipline to be two critical events in teacher-parent interactions. This shows the traditional nature of teacher-parent interactions. Ramirez [23] indicated that when communication between parents and teachers mainly revolves around student discipline or grades, it may result in mutual mistrust between them. However, this study found that when making suggestions for preservice teachers, the teachers emphasized the importance of informing parents on the good performance of their children in addition to their problems. According to the theory of action [1], teacher interactions with parents were guided by their "theories-in-use," embedded in their personal experience stories of teacher-parent interactions. However, their suggestions for preservice teachers might reveal their espoused theories related to how teachers are supposed to act in working with parents and might be learned from their preservice and in-service training. The discrepancy between teachers' theories-in-use and the espoused theories of teacher-parent interactions indicates that they may recognize the importance of and hold the knowledge of parent involvement in education, emphasized in recent educational reform policies in Taiwan, but have not yet practiced the knowledge. However, through narrating their own experience of teacher-parent interactions, the teachers were triggered to critically reflect on their theories-in-use and were aware that the nature of their communication with parents needs to change. Therefore, the programs designed for teacher professional development need to not only pay attention to knowing how to improve teacher-parent interactions, but also emphasize teachers as reflective practitioners who are capable of performing knowing-in-action, reflection-in-action, and reflection-on-reflection-in-action [26]. Because most preservice teachers might have experienced traditional teacher- parent communication while they were students in grades $\mathrm{K}-12$, it is necessary for them to understand when 
and how to interact with the parents of students to establish and maintain quality teacher-parent relationships.

Third, teacher experience of and reflection on their interactions with parents seems related to their professional identity. When the teachers decided how to interact with parents, the primary consideration was student wellbeing. When deciding whether or not they would change their action strategies if similar events occur, the teachers considered student wellbeing first. This shows the caring dimension of teaching. However, the teacher emotions and beliefs were affected by their perceptions of parents as objectors and pressure-makers. They felt that they needed self-protection and could not overly compromise themselves with parents. Hargreaves and Lasky [14] and Lasky [20] indicated a moral distance, which describes the lack of shared goals in schooling between teachers and parents and a political distance, which describes distorted interpersonal communication caused by a difference of power and status between teachers and parents. Chen and Wang [9] and Chen [8] also found that parent-teacher interactions are influenced by the sociocultural distance, moral distance, professional distance, physical distance and political distance. Epstein [13] suggested that teachers and parents are two of the three spheres of influence in the development and schooling of a child. When these two spheres are pulled apart because of the distance between them, their influence on the child decreases. However, teachers and parents have a unique influence on a child's development and these two spheres of influence do not totally overlap [13]. How to maximize the influence of teachers and parents on student development is still an important issue for study.

Finally, most of the participant teachers used their social networks when interacting with parents. In their reflections on interactions with parents, the teachers also suggested the importance of seeking help from the school administration and the advice of their senior colleagues whenever needed. However, previous research on teacher-parent interactions and parent involvement has mainly focused on parent social networks $[17,25,29]$. Therefore, one of the directions for future research is to explore what roles teacher social networks play in their interactions with parents and how the quality and quantity of teacher social relations, which result from their connection with different nodes, affect teacher-parent interactions.

\section{Limitations}

This study used open-ended questionnaires to collect qualitative data from 50 teachers of grades 1-12. Although the participants could answer freely to the open-ended questions, their responses were detached from the context in which teacher-parent interactions actually occurred. Therefore, the richness of the data may be restricted. In addition, as family structure becomes increasingly more diverse, parents are not a homogeneous group and teacher-parent interactions differ in terms of family background and history. Future research is needed to consider what roles family background plays in teacher-parent interactions, which was not emphasized in this study. Differences also exist among teachers according to the grade levels of their students, teaching experience, gender, and so on. This study did not explore how teachers of different backgrounds describe their personal experience, and future research is needed to account for these factors when investigating teacher-parent interactions.

\section{Conclusions}

Most previous studies have investigated teacher-parent interactions in grades K-6 in Taiwan and research is needed to explore how teachers interact with parents, particularly beyond the level of elementary education. This study found that student behavioral problems and academic problems were the main causes of teacher-parent interactions. When interacting with parents, the teachers perceived that parents played roles of objector, collaborator, help-wanter, and pressure-maker. The action strategies of teachers regarding their interactions with parents included handling things alone and letting someone step in. Most of the teachers expressed that they would adopt different action strategies or make some adjustment if a similar situation reoccurred. More research is needed to investigate how teachers and parents with different backgrounds influence the interactions between them.

\section{REFERENCES}

[1] Argyris, C., Putnam, R., \& McLain Smith, D. (1985). Action science. San Francisco, CA: Jossey-Bass.

[2] Bailey, C. A. (2007). A guide to qualitative field research. Thousand Oaks, CA: Pine Forge Press.

[3] Blasé, J. (1997). The micropolitics of teaching. In B. Biddle, T. L. Good, \& I. L. Good (Eds.), International handbook of teachers and teaching (Vol. II) (pp. 939-970). Dordrecht, Netherlands: Kluwer Academic Publishers.

[4] Bronfenbrenner, U. (1979). The ecology of human development. Cambridge, MA: Harvard University Press.

[5] Bronfenbrenner, U. (1994). Ecological models of human development. In T. Husten \& T. N. Postlethwaite (Eds.), The International Encyclopedia of Education (pp. 1643-1647). Oxford, UK: Pergamon Press.

[6] Centre for Educational Research and Innovation (1997). Parents as partners in schooling. Paris, France: OECD.

[7] Chang, C.-W. (2009). Study of kindergarten parent-teacher interaction: In Foucault's perspectives of power (Doctoral thesis, National Taiwan Normal University, Taipei, Taiwan). Retrieved from http://etds.lib.ntnu.edu.tw/cgi-bin/gs/ntnugs web.cgi?o $=$ dntnucdr 
[8] Chen, H.-J. (2012). A study on elementary school teacher-parent emotional distance. Journal of Teacher Education and Professional Development, 5(2), 133-154. Retrieved from http://jtepd.ncue.edu.tw/journal_swf/5 2 2 133-154.html

[9] Chen, H.-J., \& Wang, Y.-H. (2011). Emotional geographies of teacher relations: Three teachers; perceptions in Taiwan. Asia Pacific Education Review, 12, 185-195. doi:10.1007/s12564-010-9121-1

[10] Chen, Y.-M. (2009). Micropolitical analysis of parent-teacher interaction: Teacher professionalism vs. parent empowerment. Chung Cheng Educational Studies, $8(\backslash 2), 35-74$.

[11] Epstein, J. R. (1995). School/family/community partnerships: Caring for the children we share. Phi Delta Kappan, 76, 701-712.

[12] Epstein, J. R. (1996). Perspectives and previews on research and policy for school, family, and community partnerships. In A. Booth \& J. F. Dunn (Eds.), Family-school links (pp. 209-246). Mahwah, NJ: Lawrence Erlbaum Associates.

[13] Epstein, J. L. (2011). School, family, and community partnerships: Preparing educators and improving schools (2nd ed.). Boulder, CO: Westview.

[14] Hargreaves, A., \& Lasky, S. (2004). The parent gap: The emotional geographies of teachers-parent relationships. In F. Hernádez \& I. F. Goodson (Eds.), Social geographies of educational change (pp. 103-122). Dordrecht, Netherlands: Kluwer Academic Publishers.

[15] Henderson, A. T., Marburger, C. L., \& Ooms, T. (1986). Beyond the bake sale: A educator's guide to working with parents. Columbia, MD: The National Committee for Citizens in Education.

[16] Hiatt-Michael, D. B. (Ed.). (2005). Promising practices for family involvement in schooling across the continents. Greenwich, CT: Information Age Publishing.

[17] Ho, E. S. (2006). Social disparity of family involvement in Hong Kong: Effect of family resources and family network. The School Community Journal, 16(2), 7-26.

[18] Hornby, G. (2000). Improving parental involvement. London, UK: Cassell.

[19] Kohl, G. O., Lengua, L., J., McMahon, R. J. (2000). Parent involvement in school: Conceptualizing multiple dimensions and their relations with family and demographic risk factors.
Journal of School Psychology, 38, 501-523. doi: 10.1016/S0022-4405(00)00050-9

[20] Lasky, S. (2000). The cultural and emotional politics of teacher-parent interactions. Teaching and Teacher Education, 16, 843-860. doi: 10.1016/S0742-051X(00)00030-5

[21] Liang, C.-T. (2010). Micropolitical analysis of parental participation in school decision-making: Balancing the possibilities of contradictions and paradoxes. Journal of Education, 23, 127-175. Retrieved from http://www.edu.nutn.edu.tw/gac610/upload/edu23.pdf

[22] Liou, T.-H., \& Ting, H.-Y. (2008). Exploring first graders' school adjustment \& parents-teachers reactions- The perspectives of early childhood educators. Journal of National Taiwan Normal University: Education, 53(2), 131-167.

[23] Ramirez, A. Y. (2002). How parents are portrayed among educators. The School Community Journal, 12(1), 51-61.

[24] Sanders, M. G., \& Epstein, J. L. (2005). School-family-community partnerships and educational change: International perspectives. In A. Hargreaves (Ed.), Extending educational change (pp. 202-222). Dordrecht, Netherlands: Springer.

[25] Sheldon, S. B. (2002). Parents' social networks and beliefs as predictors of parent involvement. The Elementary School Journal, 102, 301-316. doi: 10.1086/499705

[26] Schon. D. (1987). Donald Schon's presentation "Educating the Reflective Practitioner" to the 1987 meeting of the American Educational Research Association. Retrieved from http://resources.educ.queensu.ca/ar/schon87.htm

[27] Shumow, L., \& Harris, W. (2000). Teachers' thinking about home-school relations in low-income urban communities. The School Community Journal, 10(1), 9-24.

[28] Swap, S. M. (1993). Developing home-school partnerships: From concepts to practice. New York, NY: Teachers College Press.

[29] Wanat, C. L. (2010). Challenges balancing collaboration and independence in home-school relationships: Analysis of parents' perceptions in one district. The School Community Journal, 20(1), 159-186.

[30] Wasserman, S., \& Faust, K. (1994). Social network analysis: Methods and applications. New York, NY: Cambridge University Press. 